\title{
General practitioners with a special interest in respiratory medicine
}

\author{
A working party of the General Practice Airways Group and the Royal College of General Practitioners
}

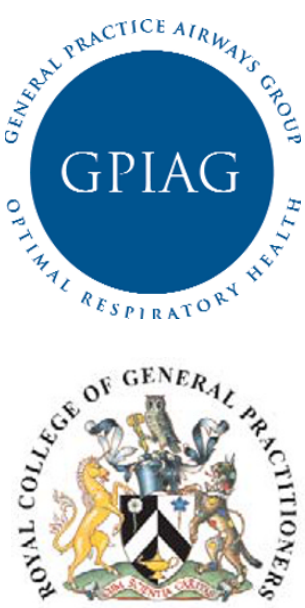

(DH) Department
of Health

WHS

Modernisation Agency

The GPIAG wishes to acknowledge the support and input from the following organisations in the development of the respiratory GPwSI document:

- The National Asthma Campaign

- National Respiratory Training Centre

- Respiratory Educational Training Centre

- British Thoracic Society

- RCN forum for respiratory nurses

- Department of Health

- Practitioners with Special Interests Team at the Modernisation Agency
$\mathrm{T}$ his GPwSI framework is one of a number, which the Department of Health has commissioned the Royal College of General Practitioners (RCGP) to write.

The RCGP has written the frameworks in conjunction with the General Practice Airways Group, General Practitioners, Consultants, PCT managers, patients, a range of organisations with an interest in respiratory medicine and the document has been amended to take their views into account. (National Asthma Campaign, National Respiratory Training Centre, Respiratory Education and Training Centre, British Thoracic Society, RCN forum for respiratory nurses, and The Department of Health and the Practitioners with Special Interests Team in the NHS Modernisation Agency.

The frameworks aim to draw on good practice and experience nationally and are intended to be advisory for the development of local services.

\section{Rationale for GPwSI in Respiratory Medicine}

Respiratory disease kills one in four people in the United Kingdom and accounts for more deaths per year than coronary heart disease or non-respiratory cancer. Respiratory problems are the most common reason to visit a GP.

This document is intended as a guide for primary care organisations (PCOs) to define the possible roles and core competencies of a GPwSI in respiratory medicine. Different PCOs will have differing needs for a respiratory GPwSI. The following is not meant to be prescriptive, but a guide for PCO's and health professionals regarding the possible roles of a GPwSI and competencies needed to achieve these roles. It complements the publications "The Burden of Lung Disease" (British Thoracic Society 2001), "Bridging the Gap - Commissioning and delivering high quality integrated respiratory healthcare" (Respiratory Alliance 2003) and "The impact of Respiratory Conditions - are Health Needs being met?" (National Respiratory Training Centre, 2002).

Whilst this document focuses on GPwSI, it is recognised that specialist nurses already play a major role in the management of respiratory conditions, and that much of what follows could equally be undertaken by an appropriately qualified specialist nurse.

\section{a. Core Activities of a GPwSI in respiratory medicine}

The core activities of a general practitioner with special interest service will vary, dependent upon local needs and resources. However they are likely to focus on:

- Asthma

- Chronic Obstructive Airways Disease

and may include:

- Allergy

- Respiratory tract infection

The pivotal role of a GPwSI in respiratory medicine is as clinical lead within PCOs, providing clinical expertise along with the necessary leadership, negotiating and co-ordinating skills to develop an integrated respiratory service according to local needs.

\section{Clinical}

Consultations with patients referred by other practitioners for advice on diagnosis and clinical management for defined respiratory problems. The scope of such advice should depend on the individual expertise of the GPwSI and on agreement with local secondary care specialists, and should depend on locally negotiated agreements about clinical responsibility.

- Development of specialised community-based services to manage respiratory disease. Examples of this could be pulmonary rehabilitation, immunotherapy for allergic disease, intermediate care beds, and palliative care.

- Monitoring of quality standards of care (in liaison with the clinical governance lead), benchmarking with other GPwSI providers and providing feedback to primary and intermediate care health professionals on quality performance.

\section{Education and Liaison}

Develop competence and confidence of professional colleagues to enable an optimal service to patients with respiratory disease.

Liaison with other health professionals in PCO to:

- advice on cost-effective prescribing (and more widely on an Area prescribing committee)

- deliver local quality targets in respiratory medicine

- give advice on matters of respiratory medicine within the PCO including commissioning

- determination of service provision in conjunction with PCO managers, secondary care providers, nurse specialists and expert patients, after an assessment of local needs.

- Liaison with local patient groups e.g. National 


\section{Not to be reproduced without the permission of the Primary Care Respiratory Journal}

Asthma Campaign and Breathe Easy Groups to provide advice on service needs and provision.

- Advice on developing uniform disease registers in respiratory disease across the PCO

- Liaison with secondary health care providers to agree service levels and provide integrated care pathways for disease management. e.g. the management of acute exacerbations of COPD, asthma or pneumonia

\section{Service Development and Leadership}

Acting as a champion and point of reference for respiratory disease and services in the $\mathrm{PCO}$

- Development of PCO-wide diagnostic services for Chronic Obstructive Pulmonary Disease, asthma, allergy and community based pneumonia.

- Co-ordination or provision of disease prevention services such as smoking cessation and influenza immunisation (in liaison with other PCO professionals)

- Develop local guidance for disease management and quality standards, which tailor national guidelines to local needs. (e.g. British Guideline on the Management of Asthma 2003, The Respiratory Alliance "Bridging the Gap" 2003).

\section{New General Practitioner Contract}

The new GP contract includes a number of quality markers relevant to the care of patients with respiratory disease. The GPwSI would have an important role in helping practices reach the quality targets as well as supporting PCO in developing and monitoring Enhanced services

\section{b. The core competencies required for a GPwSI in respiratory medicine}

These will depend on the core activities of the service provided though a GPwSI should be able to demonstrate elements of those listed below.

\section{Generalist}

The competencies required to deliver a GPwSI service should be seen as a development of generalist skills with good communication skills, competence in teaching and training health care professionals and a commitment to cascading knowledge and skills.

\section{Special interest area}

Good understanding of disease area/high standard of sound clinical knowledge and appropriate clinical skills and the following skills:

- Influencing and leadership skills

- Negotiating skills

- Understanding of commissioning

- Ability to conduct needs assessment

- Change management skills

- Public Health awareness
- Education \& Training skills

- Able to establish a practice based chronic disease register and to use it for call, recall, audit and outcome.

- Able to understand the PCO primary care education structures and networks.

\section{c. Evidence of training for the required competencies}

\section{Generalist skills}

Primary care organisations will need to ensure that the GP is a competent and experienced generalist, as well as having the specific competencies and experience for the special interest area. This can be assessed in a number of ways but is readily demonstrated by GPs who have passed the Examination of the Royal College of General Practitioners and who are also current members of the College.

and

Skilled at training health professionals and

Special interest

Evidence of working under direct supervision with a specialist clinician in relevant clinical areas. The number of sessions should be sufficient to ensure that the GPwSI is able to meet the competencies of the service requirements. For clinicians with little or no experience in respiratory medicine this will be in the order of 40 - 50 sessions.

or

Professional portfolio showing evidence of advanced clinical skills and knowledge.

and

Evidence of attendance at relevant courses or selfdirected learning to meet learning gaps identified through the professional development plan and through annual appraisal.

\section{d. Evidence of successful acquisition of competencies}

The Royal College of General Practitioners recommend that GPwSI in all areas maintain a personal development portfolio to identify learning needs matched against the competencies required for the service, and evidence of how the learning needs have been met and maintained. This portfolio will serve as a training record and will be counter-signed as appropriate by an educational mentor or supervisors to confirm the satisfactory fulfilment of the required training experience and the acquisition of the competencies enumerated in this document and others thought necessary by the employing authority. This portfolio should form part of the GPwSI annual
Composition of the

Working Party

Malcolm Campbell

GPIAG

Phil Cotton

GPIAG

Paul Everden

RCGP

\section{Clare Gerada}

RCGP

Kevin Gruffydd-Jones GPIAG

\section{Joe Neary}

RCGP

\section{Dermot Ryan}

GPIAG

\section{Bronwen Wagstaff} GPIAG

\section{Sian Williams \\ GPIAG}

Correspondence to:

Dr Kevin Gruffydd-Jones

Box Surgery

Corsham

Wiltshire

SN14 9NA

Tel +44 (0)1225 742361

Fax +44 (0)1225 742646

Email:

middlehill@gruffbox.f9.co.uk

Date submitted: 28/04/03

Date Accepted: 01/05/03

Prim Care Resp J 2003; 12(2):38-41 
appraisal.

and

Evidence of delivering a respiratory service of quality within his/her general practice.

\section{e. Evidence of maintenance of competencies}

The GPwSI would be expected to maintain his or her competencies through continued professional development and education. It is recommended that they undertake a minimum of 15 hours CPD and undergoes annual appraisal in the special interest and generalist areas.

Member of a national primary care respiratory organisation or network would add to this evidence.

General Practice Airways Group Website:

http://www.gpiag.org

\section{f. Accreditation process}

This involves determining core competencies for the special interest area, evidence required to meet these competencies and criteria for maintenance as defined in this framework. These criteria have been set nationally involving stakeholder consultation.

Before appointing a GPwSI the PCO will need to ensure that the GPwSI has met these criteria for accreditation. The mechanism for this process can be determined at local level though ideally should be through appraisal of the practitioner's personal development portfolio by both national (e.g. representative from primary care respiratory special interest group) and/or local (e.g. medical director, local specialist) appraisers.

g. The types of patients suitable for the service, including age range, symptoms, severity, minimum and maximum caseload, frequency and reason for referral.

Details will be determined at local level. It is important that the workload is such that the GPwSI is able to exercise their generalist as well as special interest skills.

In order to maintain skill, the Royal College of General Practitioners recommend that a GPwSI work at least one session per week (ideally more) in the special interest area and one session per week as a generalist practitioner (ideally more).

Patients with asthma, COPD, respiratory tract infection and allergy could form the core population. There could also be input into the care provided for patients traditionally dealt with in secondary care e.g. lung cancer, occupational lung disease. It will be important to agree across the PCO and secondary care which types of patients should be seen by GPs, the GPwSI, and secondary care.

\section{h. Local Guidelines for the use of the service}

The GPwSI would be responsible for the development, local ownership and implementation of local guidance for respiratory disease management, with other stakeholders in line with national guidelines (e.g. British Guideline on Management of Asthma 2003 and the COPD guidelines which are currently in development by National Institute of Clinical Excellence), taking into account local factors e.g. the presence of local diagnostic and treatment centres.

Local guidelines should include information for referring clinicians about:

- Types of patients to be referred to service, including inclusion and exclusion criteria.

- Referral pathways

- Response time.

- Communication pathways

i. Facilities that ideally should be present to deliver the GPwSI service in respiratory medicine

The PCO should provide administrative support and advice for the GPwSI with appropriate resources provided for education, audit and ongoing professional development. The GPwSI will need properly resourced help from other members of the PCO respiratory team e.g. smoking cessation advisers.

PCOs might consider provision of an intermediate care centre, situated for example in a community hospital or diagnostic and treatment centre with

a) diagnostic facilities such as pulmonary function testing, skin prick testing

b) out-patient clinics run by GPwSIs

c) pulmonary rehabilitation

d) intermediate care beds

j. The clinical governance, accountability and monitoring arrangements, including links with others working in the same clinical area in primary care, at PCT level and in acute trusts

The GPwSI will be accountable to the PCT Board with clinical responsibility resting with the GPwSI.

The Clinical Governance arrangements will follow those normally used for the PCT and should include systems or mechanisms for defining clinical audit and communication standards, significant event monitoring and complaint handing.

The GPwSI service would have good mechanisms for joint working and communication, including regular meetings with other service providers. 
For personal use only:

Not to be reproduced without the permission of the Primary Care Respiratory Journal

\section{k. Induction, Support and Continual Professional Development (CPD) arrangements for the GPwSI}

The induction process will include the following elements:

- Risk management

- Networking with other professionals

- Involvement in national clinical networks

- Clinical Governance arrangements

- Audit and reporting mechanisms

The GPwSI should have the appropriate funds and time for continuing professional development, including attendance at multiprofessional team meetings, audit events, relevant courses, and conferences.

\section{l. Monitoring and Clinical audit arrangements}

Priorities and targets would be set according to national and local priorities, and data collected routinely as an integral part of the service. Audit of performance in these areas and patient satisfaction would be made in conjunction with the clinical governance lead of the $\mathrm{PCO}$ and results made available for public scrutiny in an annual report.

National Asthma Campaign www.asthma.org.uk British Lung Foundation Breathe Easy Clubs www.lunguk.org/breathe

\section{Further information}

There is a range of resources available on the website http://www.gpwsi.org, - including a step by step guide to GPwSI for PCTs, and the framework for respiratory and other disease areas can be found at http://ww.gpwsi.org/frameworks.htm and http://www.gpiag.org for Bridging the Gap and other documents. 